\title{
Developmental environment of the mastership program
}

\author{
Nina A. Kornienko \\ Novosibirsk state agrarian University \\ Novosibirsk, Russia \\ kormar@tpu.ru
}

\begin{abstract}
This article reveals the developmental environment of the mastership program "Agricultural engineering", research work on the self-actualization of the personality, some studying problems of mastership students and the necessity of opening of scientific labs and centers in which mastership students could improve their development and project realization skills.
\end{abstract}

Keywords-education, upbringing, development, personality, master, research work, add-on value of a master, project implementation, the practice of project implementation.

\section{INTRODUCTION. USING THE TEMPLATE}

The educational system as an open and developing system must prove itself as any other dynamically developing systems, i. e. react fast and adequately to the changes that take place in the social development. It could possibly be so, if it was not for the interference of the current global crisis of civilization development which resulted in the fact that the education form that has been established by the end of the 20th and the beginning of the 21 st century stopped meeting the requirements of the time. "The fact that the civilization has entered a new stage of its development - the stage of an "information society" - makes the philosophers as well as the teachers think of the goals and the content of the education, formulate new goals and values which correspond with the modern society" [3].

An important role in the creation of a modern innovational economy is played by the leading branches of high technologies of Russian economy which massively affect national security, international competitiveness of the country and the improvement of state administration potential. A special place in the modernization of the educational system is taken by national research universities which act, on the one side, as a new organization form of scientific and educational activity corresponding with global scientific and educational standards, on the other side, as a form that allows to design and to implement effective educational programs of a new generation. New liberal (educational) technologies are aimed at the guaranteeing of required staffing support quality of prioritized directions of science, technology, economy branches, social sphere, which primarily affect the development and the implementation of high technologies into

\author{
Marina A. Korchuganova, Andrey P. Syrbakov, \\ Urga Technological Institute Tomsk Polytechnic University \\ Urga, Russia \\ kormar@tpu.ru
}

the production $[1$, p. 5-21]. In the conditions of a national research universities, new educational technologies implement the succession principle of higher professional and postgraduate professional education the observance of which is necessary in order to perform fundamental and applied scientific research in a wide specter of sciences.

We must take into account subjective aspects which make the process of mastership studying more and more attractive because the planning of a successful business career gains a special value for university graduates. Moreover, there is the following tendency more and more obvious: a successful competition in the labor market is conditioned by the ability of a person to realize his or her creative skills in various areas of activity, and especially in the leading areas of the sixth technological stage which act as prioritized. The mastership student is in a natural way motivated to be led in his or her practical work by creative and research work, in science, business, or other branches and structures. On the other side, the educational environment of the mastership program must act as a reserve which helps to transfer intellectual and other possibilities of a mastership student into the potentials, i. e. to start an impact of self-development, to guarantee the transfer of abilities into the reality [3, p. 4-5]. In the course of the analysis of innovational resources of a human, it is inevitable to address the main features of giftedness which is traditionally connected with intellectual initiative, creative potentials, the ability to discover new things etc. It is admitted that the giftedness significantly affects the productiveness of activity, first of all, of innovational activity.

\section{RESULTS AND DISCUSSION}

It is necessary to notice that every research in the area of human potentials, and there were many of them separated among the others (life, intellectual, personal, labor, etc.), come across one and the same "bottleneck". This means that even the most scrupulous description of the abilities (resources) of a person is less informative, because even the most carefully made list of present abilities does not allow to judge on the fact concerning the place, the time and the possibility of their use. How can a person know (realize) that this is the right moment and the right place to implement his/her abilities, his/her innovational (or any other) potential, i. e. to transfer 
present abilities to the reality? What features of the environment as a reflection of his/her improving abilities can help him/her orientate? In which form do the external conditions assert themselves as a field worth the state of forces, as a space that can be transformed with an innovational (or initiative) action?

Research work of mastership students is an integral part of the main educational mastership program and is directed to the formation of general cultural and professional competences according to the requirements of current Federal state educational standard of higher professional education and main curriculum of NSAU. There are following types and stages of performance and control over the research work of students:

- Research work planning, including the familiarization with the topics of research reviewing works in this area and the choice of research topic, composition of an abstract on the chosen topic

- Performance of research work

- Preparation of report on the research work

- Public presentation of the completed work

The main form of planning and correction of individual plans of research work of mastership students is the justification of the topic, the discussion of the plan and of intermediary results of the research within the frames of research seminars. In the course of performance of a research work as well as the presentation of its results, there is a wide discussion held at NSAU with the involvement of employers and leading scientists. This discussion helps to assess the level of acquired knowledge, skills and formed competences of students.

This is why, within the course of "Logic and methodology of science", the topics, the disciplines and the problems mentioned in the work program are considered according to the requirements of the State educational standard of higher professional education to the obligatory minimum of the content and the level of master training. For this purpose, we have prepared methodical recommendations, in which every topic includes a lecture plan, basic definitions and questions for self-evaluation represented further. The answers to these questions must be found by the students. After each topic, in order to specify and to deepen the acquired knowledge, there is a list of literature. Having studied the material, mastership students refer to the vocabulary of terms and to the recommended literature to study the discipline more properly.

The discipline "Logic and methodology of science" is designed for the familiarization of mastership students with basic philosophical and methodological positions in the modern liberal knowledge.

As a purpose of the teaching of this discipline, we see the formation of a system of knowledge and image of the logic and the methodology of agricultural engineering science by the specialists.
Based on the purpose, in the process of studying of this discipline, following tasks are solved: learning of basic ideas of modern philosophy and basic notions of modern philosophical language; familiarization with basic concepts of philosophical literature in the context of modern culture as well as with the methodological potential of modern philosophy for the psychological science; formation of a concept of the logic of agricultural engineering science and the history of scientific schools; familiarization with the system of accumulation of scientific knowledge and the methods of scientific research; learning the methods of planning and organization of experimental studies.

A master graduate of the course "110800 Agricultural engineering" must be prepared to solve following professional tasks in accordance with the specialization of mastership program and the types of professional activity: research activity: elaboration of working programs and methods of research and technical development; collection, processing, analysis and systematization of scientific and technical information on the research topic, choice of methods and means to solve this task; the choice of standard and the elaboration of individual methods of experiments and trials, analysis of their results; preparation of scientific and technical reports, reviews, publications based on the results of the performed research.

As a result of the studying of this discipline, mastership students acquire certain knowledge, abilities and skills: basic logical methods and procedures of scientific research; methodological theories and principles of modern science; methods of scientific research in the area of creation and exploitation of machines and equipment in the agrarian business; methods of empirical and theoretical cognition; statistic methods of research; planning of a multi-factor experiment.

Mastership students acquire following skills: to perform methodological grounding of a scientific research; to conduct a systematic analysis of the research object; to plan a multifactor experiment, to assess the sustainability of technical systems; to apply statistical research methods in practice; to assess random processes and functions.

Our training system of the course "110800 Agricultural engineering" is aimed at the mastering of the following: the skills of logical and methodological analysis of scientific research; the rules of problem statement in the area of liberal arts research; specific features of the subject area in liberal arts; basic methodological positions in the modern liberal cognition; requirements of the modern culture to their professional activity [8].

According to the requirements of the Federal state educational standard of higher professional education, the discipline "Logic and methodology of science" is purposed for the formation of the following general cultural (GC) and professional (PC) competences within the course "110800 Agricultural engineering". Profile 110800.68. Technology and means of mechanization of the agriculture. 
First of all, these are general cultural competences (GC): the ability to improve and to develop one's intellectual and general cultural level (GC-1); the ability to learn new research methods independently as well as to change the scientific and developmental profile of one's professional activity (GC-2); the ability to put in practice the skills of organization of research and project works (GC-4); the ability to acquire new knowledge and skills, including the knowledge from related areas, independently, using informational technologies, as well as to put them in practice (GC-6); the grasp of the principles of thinking; the ability to generalize, to analyze, to critically re-evaluate, to systematize, to forecast, to put the goals and to choose the ways of their achievement (GC-7).

As for the general professional competences (GP), mastership students must possess the following professional competences (PC): the knowledge of logical methods and procedures of scientific research; the ability to analyze modern problems of science and production in the agricultural engineering and to search for their solutions; the ability and the readiness to use the knowledge of modern research methods; the ability and the readiness to organize independent and collective research work, to search for innovational solutions in the engineering and technical area of agricultural business; the ability to perform project activities on the basis of systematic approach, the skill to build and to use models for the description and the forecasting of various phenomena, to perform their qualitative and quantitative analysis.

Self-guided work of mastership students is considered by us as one of the studying forms provided by the Federal state educational standard and by the operating curriculum in the course (speciality). The purpose of independent (out of school) work of mastership students is the learning of working methods with course books and scientific literature as well as with practical materials which are necessary for the mastering of the discipline "Logic and methodology of science"; the purpose is also to develop their skills of self-guided analysis of the received information.

The independent work consists in the performance by mastership students of reviewing works on 57 topics which allow to think deeply on the methodological problems connected with the performance of master's theses. For instance, in the studying year 2011-2012, mastership students of NSAU performed research on the following problems out of the 57 topics: "Science as an integral part of the culture"; "Logic of science: problems, structure, functions"; "Positive philosophy and science: external world and the problems of cognition"; "The structure of scientific revolutions' by $\mathrm{T}$. Kuhn"; "Evolutional concept of science by S. Toulmin"; "Criteria, standards and ideals of scientific cognition"; "Scientific hypothesis: structure, functions, interpretation, requirements, building and selection principles"; "Creative process in science and its stages"; "Genius and geniality in science"; "The nature and the technology of scientific discoveries"; "Systematic research method: advantages and specific features"; "'Chaos' and 'order': synergetic solution of a problem"; "Classical and probability determinism";
"Reductionism and the ontology of elementarism"; "The ideals of science and scientific rationality"; "Concerning the relation of the natural and artificial intelligence"; "Synergetic method as a theory of self-organization"; "The problem of reality in the modern science. Levels and forms of organization of the reality"; "Scientific cognition and the values of the industrial civilization"; "The philosophy of foundations of a scientific theory".

In the years 2013-2014, following problems were researched: "The development tendencies of the methodology of science at the turn of the 20th and the 21st centuries"; "Methodology of science: problems, structure, functions"; "Problems of relation of ordinary and scientific cognition"; "Concerning the relation of problematic situations and development problems of science"; "Scientific revolutions and the method of hypotheses"; "The nature and the technology of a scientific discovery"; "Artificial intelligence as a phenomenon of the modern culture"; "The fundamentals of science and their structure"; "Ideals of science and scientific rationality" [6].

Out of 59 topics in the year 2015, mastership students of NSAU chose 30 topics concerning the problems that had not been researched by them before. These are: "Logic of science: problems, structure, functions"; "Methodology of science: problems, structure, functions"; "Criteria, standards and ideals of scientific cognition"; "Basic concepts and approach to the notion of the truth in the philosophy of science of the 20th century"; "The process of scientific search: structure, stages and means"; "Scientific problem: genesis and the methodology of solution"; "Scientific revolutions and the hypothesis method"; "The theoretical and the empirical issues in the modern scientific cognition"; "Creative process in science and its stages"; "The nature and the technology of scientific discovery"; "The personality development of the President of Russia"; "Value perception of a personality", etc. They presented them, prepared scientific publications and presentations of their articles. I have witnessed the delight in students' eyes caused by their first mastership research.

The training of masters widely influences the development of Russian society and primarily favors the growth of Russian science, culture, and the creation of an innovational economy in Russia.

In the Federal state educational standard of the third generation, it is noted that a student must know, be able, master. The terms that we are accustomed to, "be able" and "master", are very close by their dialect, the differentiation between them is quite facultative, and that is why the confusion of terms results in the elaboration of blurred, and thus unrealizable requirements to the masters' training [5]. This is only further confirmed in term of the fact that most of the competences are defined by the university. As a result, there are unrealizable requirements to the graduated masters, for example, a master should be able to analyze modern scientific and production problems in the agricultural engineering and to search for their solutions. The question arises, if a mastership graduate, who has only studied for two 
years after his/her bachelor's graduation, is able to do this without a proper practical experience. The university has also additional difficulties, i. e. lots of unreal requirements to the students than challenge the accreditation of the university and the assessment of students. It would be more correctly to set the following formula: a master's degree graduate must know, be able, possess and implement his/her projects made within the period of his/her mastership studies. Such requirements are targeted at the increase of an innovational development level of Russian economy by means of the inflow of new ideas and practical developments of mastership graduates [7].

Currently, there are various criteria of the working quality of higher educational institutions; moreover, according to many scientists and experts, the main factors are depicted in the monitoring results of Russian higher educational institutions: these are the real added value of graduates as well as the added value created by scientific and pedagogical elaborations, the growth of qualification and the intellectual potential of the staff of educational system, academic mobility of the academic teaching staff and students. Of course, each of the listed criteria includes a number of additional factors which form one of the developed theories of modern economy, the concept of added value, the essence of which consists in the creation of services and products in proportion to the invested labor, intellectual, material resources; hereby, the added value of a service, the scope of which is defined by the quality of invested resources and the art of management of its creation processes [8]. The added value of mastership graduates is an additional complex of useful qualities such as knowledge, creative abilities, skills, and competences acquired in the process of study; this added value creates the conditions for an effective and innovational development of economy, educational system, and science. The task of a higher educational institution is to invest such theoretical and practical knowledge into mastership students that would help give a stimulus to the development of business structures of regions; thus, such graduates will be obviously highdemanded which, as a result, will positively affect the image of certain educational institution and raise the number of students (fig. 1).

As seen from the structure of the added value of masters' training, new information, skills, new knowledge, abilities of creative thinking as well as ability to implement projects form fresh competences that include the ability to practically transform inner potential and the knowledge of a person into the ability to solve professional and general tasks [4].

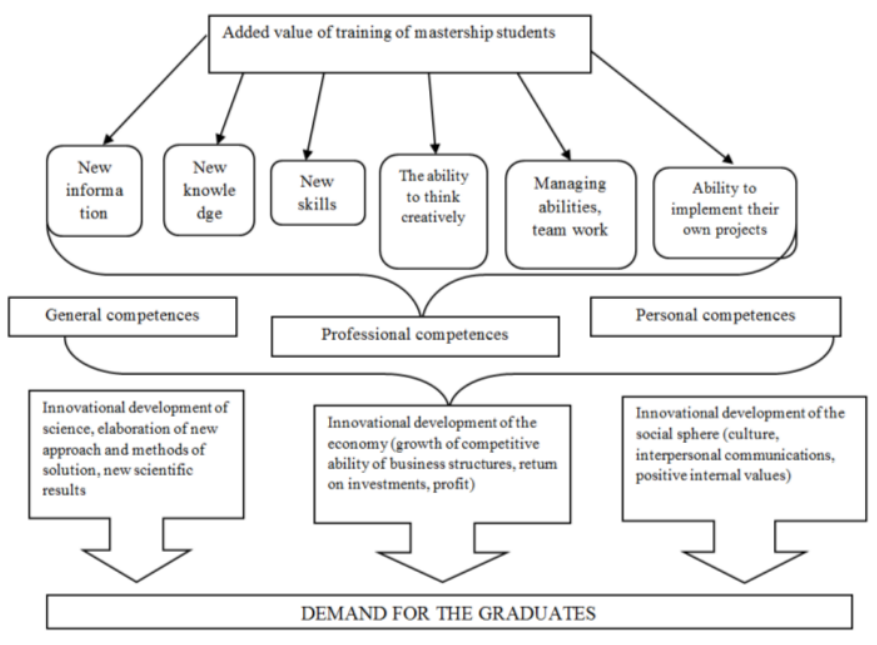

Fig. 1: Structure of the added value of mastership students training and the demand for them

\section{CONCLUSION}

The scope of the created added value of mastership training can be evaluated on the basis of the following criteria:

- Salary level after graduation from a mastership program

- The degree of preference of masters by business structures which employ them

- Time spent for the training of masters

- The quality of academic and research modules prepared by the academic staff

- Final results of training (scientific publications, growth of the economy of business structures, elaboration of innovational projects, development of social sphere)

One of the most reliable and simple criteria is the assessment according to career progress and salary level of mastership program graduates which is based on the hypothesis that a more skilled labor is well paid. However, in Russia as well as in many foreign countries, this logic does not correspond with the reality. Currently, the highest levels of income are typical for the spheres that are not only hardly connected with innovations, but, quite on the contrary, are the reasons of global crisis; in particular, these are securities markets and banking. Nevertheless, the circularity of economic development makes the whole world turn to innovations.

In the United States, they consider to be effective the methodology of exploration of needs of the firms in mastership graduates, and the revealing of their preferences and priorities on the basis of a complex questioning of managing staff.

In France, Higher commercial management school applies the strategy of development of innovational activity of masters by means of creation and their involvement into the work of non-commercial associations which yearly execute the orders of business-structures. In these associations, various student 
centers appear: consulting, marketing, informational centers. The materials of term papers, masters' papers as well as special-order scientific research and projects are introduced into production. For this, there was a research lab created at the Higher commercial management school that includes three teams:

- Entrepreneurship and management

- Marketing and strategy

- Finance, economy and law [6]

In many higher educational institutions of Russia, there were created and are working learning and scientific labs that give the opportunity to use them for scientific and practical purposes. The students working at these labs master practical skills of introduction of scientific projects; this builds the basis of development of interdisciplinary connections.

As distinct from Russian firms that are used to gain all intellectual products for free, abroad, every research is paid. We have no practice of targeted orders and the financing of innovational projects at higher educational institutions by business structures; selection and assessment of future staff among the graduates is rather an exception from the rule.

Basic educational mastership program includes the publication of a minimum of three scientific articles; however, their value is not assessed by anyone, not even by mastership students themselves. The work is conducted primarily within the frames of a discipline and does not find application later. Nonetheless, many papers are of great interest. We must educate not only a master who is able to write a scientific article or a make a project, but a master who is able to organize scientific work in a group, who can apply the methods of team work. This problem can be solved by means of organization of scientific laboratories and centers at educational institutions where the students could perform all basic functions of business structures, including the planning and the realization of research works. Moreover, it is preferable to appoint students as directors of scientific laboratories or centers. In scientific labs, mastership students should organize complex research with the participation of students of various programs.

Experience has shown that the creation of such laboratories is possible; it does not require large additional expenses but gives the opportunity to mastership students to go through all stages of development and introduction of scientific projects. Besides, the students receive new opportunities of planning, control and formation of researchers out of mastership students which helps promote their career and raises scientific potential of universities.

The creation of scientific labs and centers with the participation of mastership students and their involvement into scientific teams help eliminate the existing paradox of masters' training. Currently, the science develops in teams, while mastership students work alone. It is rational to introduce a gradation in masters' diplomas, for example, to emphasize about 5-10\% out of the total count of mastership program graduates as the highest category. This can create the conditions of selection of the most talented mastership students and draw attention of management of business structures to them where they could possibly be employed.

In fact, specialists and masters belong to the same educational level. This is why many people are interested if a master's degree is "higher" or "lower" than a specialist's degree. Of course, there are structural differences of educational programs which provide a significantly higher volume of research and independent work of mastership students than of specialist program students; however, it is rather a disadvantage nowadays because these particular types of activity have become the weakest part of training process as they are still poorly organized and are characterized by low methodological support. Thus, the main directions of educational quality improvement of mastership programs must be the following key events [2]:

- Improvement of organization of self-guided work of mastership students

- Search for optimized organization forms of research work within the mastership program and its staff, informational as well as logistical support

- Increase of the level of technical training of masters, especially those who study in other courses

As the result, within the frames of Bologna educational model, where mastership programs connect research activities with higher education, mastership programs must be variously oriented. Only in this way professional mastership programs will be considered as the final part of higher education.

\section{REFERENCES}

[1] Galazhinsky E. V., Klochko V. E. High humanitarian technologies in education: between humanism and manipulation// educational Psychology. 2010.№12.

[2] Kibanov A. J., Zvonnikov V. I. problems of training of specialists in the field of personnel management // Higher education.-2010.-No. 10.

[3] V. E. Klochko, O. M. Krasnoyartsev Signs of a developing educational environment for graduate research University// educational Psychology.2013, no. 4

[4] Cracklin T. F. Urgent problems of reforming the higher professional education in Russia// Bulletin of the Altai Academy of Economics and law. -2011.№2-. S. 67-69.

[5] Kornienko N. And. The logic and methodology of science: problems of modern scientific methodology// Innovative potential of subjects of educational space in the conditions of modernization of education. Materials of IV International scientific-practical conference (21-22 November 2013, Russia, Rostov-on-don, part 1, p. 40-43).

[6] Modernization of Russia in the context of globalization // World economy international relations.-2012. -No. 3.-S. pp. 105-117.

[7] Salnikov V. Actual problems of development of higher school in the conditions of reform of education// Alma mater. -2005.10. P.11.

[8] 8. Stroiteleva T. T. About the problems of masters ' training in modern conditions// Bulletin of fsbei HPE University of management, Moscow: in 2014. p. $275-279$. 